\section{High risk of systemic lupus erythematosus development in patients with ITP: antiphospholipid syndrome is also a concern}

Zhu et al in their elegant population-based cohort study investigated the development of systemic lupus erythematosus (SLE) in patients with idiopathic (immune) thrombocytopenic purpura (ITP) and demonstrated the significantly higher risk compared with the control population. ${ }^{1}$ They rightfully used sensitivity analysis and treatment data to improve the accuracy of clinical diagnosis. Despite this effort, the difficulty remains to compare epidemiological studies using self-reported diagnosis, health records or using classification criteria. ${ }^{2}$ In clinical practice, lack of a generally acknowledged diagnostic criteria might lead to SLE diagnosis of cases like undifferentiated connective tissue disease that may be treated similarly. ${ }^{3}$

Additionally, Zhu et al also provided important data on the association of antiphospholipid syndrome (APS) with ITP. They identified 20 cases of APS in the ITP group (2.77\%) compared with $3(0.02 \%)$ in the control group which was more frequent than any other autoimmune condition in their comorbidity list. The comorbidity list in table 1 included coronary artery disease and cerebral vascular accidents but not thrombosis, pulmonary embolism or pregnancy loss that might help further to identify additional risk of APS in these patients. ${ }^{1}$

APS is characterised by arterial and/or venous thrombosis and/ or obstetric morbidities. Thrombocytopenia is the most common haematological manifestation of APS, although severe thrombocytopenia and bleeding are rare. ${ }^{4}$ Most importantly, moderate thrombocytopenia does not prevent the development of thrombosis. ${ }^{4}$ Data regarding the risk of thrombosis in patients with ITP and positive antiphospholipid autoantibodies (aPL) are controversial. ${ }^{4}$ We have previously shown in a controlled study that patients with ITP and positive aPL, especially positive for lupus anticoagulant, developed clinical features of APS (mostly thrombosis) during long-term follow-up. ${ }^{5}$

Fanouriakis et al further discussed the issue of assessment of patients with ITP from the point of systemic autoimmune disease and nicely stressed the importance of initial immunological testing including aPL in their accompanying editorial. ${ }^{6}$ We agree with Fanouriakis et al, and kindly suggest to add the APS (with or without SLE) among others to figure 1 as a significant possibility of another path of evolution of the disease with important consequences.

We would like to emphasise that in some patients with an initial diagnosis of ITP, features of SLE and/or APS may develop.
A baseline assessment of patients with ITP for systemic clinical manifestations should be undertaken and relevant autoimmune serology including aPL profile should be searched.

Murat İnanç ๑ , ${ }^{1}$ Bahar Artim-Esen, ${ }^{1}$ Reyhan Diz-Küçükkaya ${ }^{2}$

${ }^{1}$ Istanbul Faculty of Medicine, Department of Internal Medicine, Division of Rheumatology, Istanbul University, Fatih, Istanbul, Turkey

${ }^{2}$ Faculty of Science, Department of Molecular Biology and Genetics, Istanbul University, Fatih, Istanbul, Turkey

Correspondence to Dr Murat Inanç, Istanbul Faculty of Medicine, Department of Internal Medicine, Division of Rheumatology, Istanbul University, Fatih 34390, Istanbul, Turkey; drinanc@istanbul.edu.tr

Contributors $\mathrm{Ml}$ drafted the letter and it was reviewed and approved by all authors.

Funding The authors have not declared a specific grant for this research from any funding agency in the public, commercial or not-for-profit sectors.

Competing interests None declared.

Patient and public involvement Patients and/or the public were not involved in the design, or conduct, or reporting, or dissemination plans of this research.

Patient consent for publication Not required.

Provenance and peer review Not commissioned; internally peer reviewed.

(c) Author(s) (or their employer(s)) 2020. No commercial re-use. See rights and permissions. Published by BMJ.

$$
\text { Check for updates }
$$

To cite İnanç M, Artim-Esen B, Diz-Küçükkaya R. Ann Rheum Dis Epub ahead of print: [please include Day Month Year]. doi:10.1136/annrheumdis-2020-218345

Received 19 June 2020

Accepted 20 June 2020

Ann Rheum Dis 2020;0:1. doi:10.1136/annrheumdis-2020-218345

ORCID iD

Murat İnanç http://orcid.org/0000-0002-6376-5583

\section{REFERENCES}

1 Zhu F-X, Huang J-Y, Ye Z, et al. Risk of systemic lupus erythematosus in patients with idiopathic thrombocytopenic purpura: a population-based cohort study. Ann Rheum Dis 2020;79:annrheumdis-2020-217013-799.

2 Pons-Estel GJ, Alarcón GS, Scofield L, et al. Understanding the epidemiology and progression of systemic lupus erythematosus. Semin Arthritis Rheum 2010;39:257-68.

3 Bertsias GK, Pamfil C, Fanouriakis A, et al. Diagnostic criteria for systemic lupus erythematosus: has the time come? Nat Rev Rheumatol 2013;9:687-94.

4 Artım-Esen B, Diz-Küçükkaya R, Inanç M. The significance and management of thrombocytopenia in antiphospholipid syndrome. Curr Rheumatol Rep 2015;17:14.

5 Diz-Küçükkaya R, Hacihanefioğlu A, Yenerel M, et al. Antiphospholipid antibodies and antiphospholipid syndrome in patients presenting with immune thrombocytopenic purpura: a prospective cohort study. Blood 2001;98:1760-4.

6 Fanouriakis A, Bertsias G, Boumpas DT. Population-based studies in systemic lupus erythematosus: immune thrombocytopenic purpura or 'blood-dominant' lupus? Ann Rheum Dis 2020;79:683-84. 